\title{
YOUNG CHILDREN'S SOCIAL RELATIONSHIPS WITH SIBLINGS AND FRIENDS
}

\author{
Brenda L. Volling, Ph. D., Lise M. Youngblade, Ph.D., Jay Belsky, Ph.D.
}

Relationships with a close friend and a younger sibling were investigated in 30 first-born young children. Greater positive affect and reciprocity were found between friends than between siblings. Limited support for the consistency of individual differences in relationship quality across friend and sibling dyads was also revealed. Implications for child development and future research are discussed.

$\mathrm{T}$ he role of peer relationships for young children's social and sociocognitive development has been of long standing interest. Several theories hold that relations with same-age peers contribute to the development of children's interpersonal competence, conflict-resolution skills, perspective-taking, and social-reasoning skills ( $P$ iaget, 1932; Sullivan, 1953; Youniss, 1980). Indeed, poor peer relationships and peer rejection in childhood have been associated with subsequent social difficulties in adolescence and adulthood (Parker \& Asher, 1987). Most peer relationship studies with children focus either on peer acceptance (e.g., popularity) or the development of close friendships. The intimacy and familiarity characteristic of children's close friendships are thought to facilitate the development of a good sense of perspective, interpersonal sensitivity, and companionship (Furman \& Buhrmester, 1985; Parker \& Gottman, 1989). Peer-group status and dy- adic friendships are viewed as distinct domains of children's peer relationships ( $B u$ kowski \& Hoza, 1989; Parker \& Asher, 1992), and recent work by Parker and Asher (1993) has found that the quality of children's close friendships in middle childhood predict their feelings of loneliness above and beyond the effect of peer-group acceptance.

In addition to the close relationships formed with friends, the sibling relationship is also considered influential in the development of young children's social and emotional understanding (Dunn 1983, 1988; Howe, 1991). In fact, children's performance on perspective-taking tasks has been related to individual differences in cooperative and affectionate interaction between preschool siblings (Dunn, Brown, Slomkowski, Tesla, \& Youngblade, 1991). Patterson (1986) has reported that the relationship can also serve as a training ground for the development of aggressive behavior,

A revised version of a paper submitted to the Journal in July 1995 . Research was partially funded by a Dissertation Research Award from the American Psychological Association to the first author, and by grant ROIHD15496 from the National Institute of Child Health and Ituman Development to the third author. Authors are at: Department of Psychology, University of Michigan, Ann Arbor (Volling, Youngblade): and Department of Human Development and Family Studies, Pennsylvania State University. University Park (Belsky). 
and Stocker (1994) found that sibling rivalry was associated with greater loneliness and depression, as well as feelings of low self-worth, in second graders.

The importance of friendships and sibling relationships for children's psychological adjustment is now emerging, but few studies have addressed the interplay between children's friendships and sibling relationships. Recent research has focused on the linkages between family and peer relationships (Pettit. Dodge, \& Brown, 1988; Pettit, Harrist, Bates, \& Dodge, 1991; Parke \& Ladd, 1992; Puttalaz, 1987), but much of it has examined links with peer-group acceptance rather than the quality of the children's friendships. Moreover, with the notable exception of studies by Stocker and Dunn (1990) and Stocker (1994), most of this work has addressed the associations between parent-child and peer relationships and overlooked the connection between sibling and peer relationships. Interaction between parents and children is often complementary, whereas that between siblings, due to the smaller difference in age, is usually more reciprocal and egalitarian (Dunn, 1983). Thus, the interaction among children, theoretically important for the development of social-cognitive abilities (Piaget. 1932; Sullivan, 1953), is likely to include that among siblings, as well as among peers. This being so, it would be reasonable to expect similarities across friendships and sibling relationships, particularly since both are relatively intense dyadic relationships.

Because siblings differ in age, and older children are often more dominant in their interactions with a younger sibling, their interaction may be complementary, as well as reciprocal (Dunn, 1983). Therefore, children's interactions with younger siblings may be quite different from those with friends of the same age. In addition, the characteristics and interaction histories of dyadic participants (Hinde, 1979) will engender for each a different relationship with a sibling than with a friend.
The study reported in this article was part of a larger, longitudinal investigation of children's social development and family relationships (Belsky, Youngblade, Rovine, \& Volling, 1991). The present study sought to compare and contrast the relationships of first-born, preschool children with a younger sibling and a close friend. To this end, the study sought to examine the reciprocal and complementary nature of preschool children's relationships with a friend and a younger sibling; to determine whether there were differences in affective quality across sibling and friend dyads; and to investigate consistency in individual differences across young children's friendships and sibling relationships.

\section{METHOD}

\section{Subjects}

Subjects initially included 30 first-born Caucasian children, their second-born siblings, and the first-born siblings' closest friend. Information on the children was gathered at two points in time over the course of the larger study. Families had initially been recruited during the last trimester of the mother's pregnancy with the first-born child and followed in detail through the first year of the child's life (Belsky, Gilstrap, \& Rovine, 1984). They were later contacted and invited to participate in two follow-up investigations, first when the older siblings were five (friendship data collection phase), and second when they were approximately six (sibling data collection phase) years of age.

All the sibling families were maritally intact, were either working- or middleclass, and had a mean family income of $\$ 33,454$ at the time of the sibling phase of the project. Fathers averaged 34.6 years and mothers 32.6 years of age, while their average education was 16 years and 15 years, respectively, at this time.

At the time of the friendship data collection, when the older sibling was five years old, four of the 30 families declined to participate; thus only 26 of the older siblings 
were observed with their close friend. The mean age of the first-born child's closest friend was 4.9 years (range 4-6 years). Twelve of the 15 first-born boys had samesex friends, and three an opposite-sex friend; nine of the 11 first-born girls had a same-sex friend and two an opposite-sex friend. The children had been friends, on average, for 38 months ( $S D=18$ months).

The same 26 families participated in the sibling data collection. At that time, the older siblings averaged six years of age (range 65-79 months), while their younger siblings averaged 39.8 months (range $21-$ 56 months). The sibling dyads consisted of seven brother and six sister pairs, eight older brother-younger sister pairs, and five older sister-younger brother pairs.

\section{Procedure}

The 26 five-year-olds were interviewed with their close friend in a two-hour laboratory situation (Youngblade \& Belsky, 1992) during which the first-borns were asked about their feelings with respect to both their close friend and their younger sibling. Maternal reports of quality of the friendship were also collected at this time.

When the older child reached approximately six years of age, all families from the larger study who had at least two preschool children were contacted for the sibling phase (Volling \& Belsky, 1992). Two one-hour home observations were then conducted in which children were observed interacting with their second-born sibling. Maternal reports of the quality of the sibling relationship were gathered at this time. Complete sibling and friend data were available for 26 children.

A notable limit to the research design is the possibility of a confound between age and the relationship assessed. Because the data are from an already existing data set, no correction was possible. However, many theoretical frameworks focusing on the development of children's social relationships, most notably those with peers and friends (Parker \& Gottman, 1989;
Yeates \& Selman, 1989; Youniss, 1980), do not propose substantial changes across the early childhood period.

\section{Measures: Friendship}

Laboratory observations of friendship. Data for the current report were taken from the two free-play episodes of the eight comprising the fifth-laboratory observation procedure, since they most closely resembled the free-play sessions between siblings during home visits a year later. In the first, ten-minute, unrestricted free-play episode, the children were shown four sets of toys from which they jointly chose one. They were then left alone to play as they wished. In the second, 20-minute, restricted free-play episode, several sets of toys chosen to facilitate pretend play were placed on a blanket and the children were told they could play with any of the toys but should stay on the blanket (no effort was made to stop them wandering away). From the videotape of the interaction, independent observers coded both the dyadic quality of the friendship and the behavior of each child every 30 seconds, using fivepoint rating scales. Cohen's kappa coefficients of inter-rater reliability ranged from .60 to .77 , with a mean of .65 .

Three ratings of dyadic friendship quality were used: /) positive connectednessinteraction that included joint pleasure, giggling, and laughing; 2) negative connectedness - interaction that included conflicts, disagreements, and aversive exchanges; and 3) joint cognitive sophistication in play-the quality of the children's play that showed how much cognitive complexity the pair could manage collectively (e.g., sustained sequences of pretend play). Dyadic ratings were reduced, first by summing each 30 -second rating to create a within-episode score, then by summing across the restricted and unrestricted freeplay episodes to create composites of dyad positivity, dyad negativity, and joint fantasy play.

Behavior of both the target child and the 
friend were rated on three dimensions: I) negative initiations-spontaneous negative or aversive bids (e.g., stealing toys) to the other child that were not simply responses to the other child's actions; 2) positive initiations-spontaneous prosocial bids (e.g., sharing) to the other child that were not in response to the other child's actions; and 3) positive reactions-prosocial behavior exhibited by either child in response to a bid by the other child (e.g., helping). Ratings were summed to form total scores of negative initiations, positive initiations, and positive reactions. To create close-to-equivalent variables across the sibling and friend dyads, the positive initiation and positive reaction variables were summed together to create a prosocial behavior score for both the child and the friend. In an effort to reduce the ratio of subject to variable and to increase construct validity (Rushton, Brainerd, \& Pressley, 1983), all scores were then standardized and summed to create the following two composites: 1) friendship conflict - the sum of dyad negativity and negative initiations by each of the children; and 2) friendship cooperation-the sum of dyadic positivity, joint fantasy play, and prosocial behavior by each of the children.

Children's feelings. At the five-year assessment, first-born children were also administered the Smile Instrument (Youngblade, 1990) which was adapted from the Emotional Quality Subscale (EQS) of the Rochester Assessment Package for Schools (Wellborn \& Connell, 1987). The EQS was designed to assess children's emotions in close relationships, and internal consistency estimates in previous work have ranged from .75 to .84 (Mellor-Crummey, 1989). Children were asked how they felt when they were with their sibling and when they were with their friend. Four emotions (happy, sad, excited, and angry) were rated by the child by pointing to drawings of faces displaying each emotion. Verbal descriptions were given of each face (often angry, pretty angry, sometimes angry, never angry). High scores indicated more anger, sadness, excitement, or happiness. The happy and excited scores were combined to form composites of positive feelings about the close friend and younger sibling; the sad and angry scores were summed to create a composite of negative feelings.

Maternal reports. Mothers were asked to rate eight items that described friendship between the children, using five-point rating scales from $1=$ never to $5=$ =always. A Friendly scale was created by summing together three items that described how much the children shared with each other, had fun together, and enjoyed each other's company (Cronbach's alpha $=65$ ). An Unfriendly scale was created from five items describing how much or often the children yelled, hit, teased, tattled on, and disliked each other (Cronbach's alpha=.73).

Intercorrelations between all the measures of children's friendships (i.e., observations, child's feelings, and maternal reports) revealed no significant associations.

\section{Measures: Sibling Relationship}

Home observations. When the older child was six years old, two one-hour home observations of sibling interaction were scheduled, two weeks apart. Siblings were invited to play with one of two Fisher-Price play sets brought to the home by the observer, along with a bag of toys (e.g., baby doll, spaceship). Each visit was audiotaped.

Based on observational research by Pettit and Bates (1990), four behavioral events were identified as relevant to the study of sibling interaction: dyadic conflict, shared positive affect, prosocial behavior, and the level of playful dyadic engagement. Each event was written up at the time of occurrence, and these records were supplemented later by reviewing the audiotape. Sibling interaction was then coded by three independent raters who had not coded prior information on the friendship dyads. Interrater reliability, calculated on a random ten of the total 60 records of home observa- 
tions using Cohen's kappa, ranged from .52 to .81 , with a mean of .71 .

Each conflict between siblings was rated on a five-point scale ranging from $\mathrm{I}=$ unreciprocated agonistic behavior with minimal negative affect (e.g., one child taking a toy with no resistance from the other) to $5=$ highly destructive and hostile encounters between siblings. The initiator of the conflict episode was also noted. Total scores for conflict inititations and the dyadic conflict ratings were created by summing across the two home visits, and a composite score of sibling conflict was formed by standardizing each variable and summing them together.

To assess the cooperative nature of sibling interaction, prosocial inititations, level of sibling play, and shared positive affect were coded from the behavioral records. Each initiation of a prosocial act (e.g., teaching, comforting) was noted and later coded from the behavioral record. Similarly, the extent of shared positive affect between siblings was rated from the narrative transcripts along a three-point scale, from $1=$ exchange of only brief smiles to $3=$ frequent sharing of positive affect and mutual enjoyment (e.g., laughing during fantasy play).

Sibling play episodes were also noted and later coded as follows for engagement level: I) nonsocial play - children not in close proximity, each focused on individual tasks; 2) bystander play-one focused on an activity and the other watching nearby; 3) parallel play - both focused on a joint activity but no reciprocal interaction involving turn-taking; 4) cooperative playboth involved in play with a common goal involving turn-taking; and 5) cooperative pretend play - both cooperatively engaged in a shared fantasy theme. Total scores were created by summing across the two visits, and a composite of sibling cooperation was formed after standardizing each variable and summing together the scores on prosocial initiations (older and younger sibling) with the play and positive affect ratings.
Maternal reports. Mothers of the siblings were asked to rate eight items on a five-point scale, ranging from $1=$ never to $5=$ always, to describe the quality of the sibling relationship. The items were identical to those they completed at the five-year phase for quality of friendship, and included a Friendly (Cronbach's alpha=.66) and an Unfriendly (Cronbach's alpha $=.63$ ) dimension of the sibling relationship.

Intercorrelations calculated among the sibling relationship variables (e.g., observations, maternal, and child reports) revealed several significant associations. First, sixth-year maternal reports of Friendly sibling behavior were inversely related to maternal reports of Unfriendly sibling behavior $(r=-.46, p<.01)$. First-born children's reports of negative feelings about their siblings at five years were inversely related to their positive feelings about those siblings $(r=-59, p<.01)$, and positively associated with their mother's reports of Friendly sibling behavior at six years $(r=$ $.51, p<.01$ ).

\section{RESULTS}

\section{Preliminary Analyses}

The first set of analyses examined the associations between various family structure variables (i.e., age and gender of the child, age difference between siblings) and the sibling and friend measures. A s.ries of 2 (older sibling gender) $\times 2$ (younger sibling gender) ANOVAs using the sibling relationship variables revealed no significant main effects or interactions of the children's gender. Therefore, the combined sample was used in all subsequent analyses. The small number of children with opposite-sex friends precluded a similar analysis for the friendship variables.

No significant associations were found between the age difference of the siblings and any of the relationship indicators for friends or siblings, but significant positive correlations were found between the age of the older child and observed sibling cooperation $(r=.42, p<.05)$ and observed friend 
cooperation $(r=.47, p<.05)$. In all subsequent analyses using the observational measures of sibling and friend cooperation, the age of the older child was statistically controlled.

\section{Reciprocity in Relationships}

To discover whether children's role in their relationship with their younger sibling differed from that with the close friend, mean differences were examined in the prosocial and conflict behavior of each child with the friend and with the sibling. Paired $t$-tests revealed significant differences in the frequency that prosocial acts, $t(29)=8.38, p<.0001$, and conflict, $t(29)=$ $3.24, p<.01$, were initiated by the older and younger sibling. Older siblings were significantly more likely than their younger siblings to initiate prosocial ( $M=7.23$ vs. $1.93)$ and conflict behavior ( $M=19.23$ vs. 12.36). No significant mean differences were found in the extent to which prosocial or agonistic behavior was exchanged between the first-born child and the close friend.

Differences in sibling and friend relationships were further investigated by conducting paired $t$-tests for the children's reports of negative and positive feelings, and for their mothers' reports of friendly and unfriendly interaction. The standardized observational measures were not included in this analysis, as standardization of the variables set the means for these composites to zero and mean comparisons were therefore not possible. Significant differences were apparent for the child's reports of positive feelings toward sibling and friend, $t(22)=-2.18, p<.05$, and for the mother's reports of both Friendly behavior, $t(25)=-.76, p<.0001$, and Unfriendly behavjor $t(25)=8.10, p<.0001$. First-born children reported more positive feelings about their friends $(M=7.0, S D=1.4)$ than they did about their younger siblings at five years $(M=6.0, S D=2.1)$. Similarly, their mothers reported more friendly behavior between friends at five years $(M=13.0, S D=1.2)$ than between siblings at six years $(M=11.6$, $S D=1.1)$ and more unfriendly behavior between siblings at six years $(M=16.1, S D=$ 2.0) than between friends at five years $(M=10.5, S D=2.9)$.

\section{Individual Differences in Relationships}

In examining consistency across relationships, correlations between the friend and sibling variables revealed that when first-born children reported more negative feelings for their friend at five years, they were more likely to cooperate with a sibling at six years (partial $r=.42, p \leq .05$ ). In addition, when mothers reported more friendly relations between the two friends at five years, the older children were significantly more likely to report negative feelings for their younger sibling at this time $(r=.50$, $p<.01$ ). Mothers' reports of positive friendship quality at five years were positively correlated with their reports of friendly sibling relations at six years $(r=.49, p<.01)$. There was also a marginal association between laboratory observations of friend conflict at five years and home observations of sibling conflict at six years $(r=.33$, $p<.10$ ). In addition, children who reported more positive feelings about their close friend at five years were also observed in significantly less sibling conflict at six years $(r=-.45, p<.05)$, and to have mothers who reported less unfriendly behavior between the siblings $(r=-.46, p<.05)$. In sum, the correlational findings provided rather limited evidence for consistency across sibling and friend relationships.

\section{DISCUSSION}

The findings from the current study suggest that young children's relationships with a close friend are more reciprocal and egalitarian than those with a younger sibling. Older siblings were much more likely to initiate conflict and prosocial behavior while interacting with their younger sibling, but displayed no differences in the extent of negative and positive behavior initiated with the friend. The finding that older 
siblings initiated more conflict and prosocial behavior than did younger siblings is consistent with earlier studies documenting the leadership role played by older children in such relationships (Abramovitch, Corter, \& Lando, 1979; Dunn \& Kendrick, 1982; Lamb, 1978). The current results contribute to the existing literature in documenting more reciprocal interactions of young children with a close friend than with a younger sibling - a finding similar to that reported in samples of school-age children (Brody, Stoneman, \& MacKinnon, 1982).

Because differences in reciprocity and complementarity exist across the sibling and friend dyads, each of these relationships may make a unique contribution to children's social development and psychological adjustment. Consistent with Piagetian notions, the reciprocity found between close friends in this study may foster the development of children's interpersonal sensitivity, moral reasoning skills, and perspective-taking. The asymmetry noted between siblings suggests that sibling interaction may have potentially different developmental implications for older and younger children in the family. Indeed, this asymmetry in sibling interaction is often underscored by behavioral geneticists as an aspect of the nonshared family environment responsible, in part, for differences in personality, intelligence, and psychopathology between siblings (Dunn \& Plomin, 1990; Plomin \& Daniels, 1987). In other words, these behavioral differences between siblings provide different interactive contexts for the two children (e.g., the older is bossier and more controlling to the younger), and this can result in different developmental outcomes for each child.

Not only did sibling and friend dyads differ with respect to the reciprocity of interaction between participants, but the affective nature of these relationships also differed. Friendships were seen by mothers as more friendly and less unfriendly than were children's sibling relationships, and older children were likely to report more positive feelings about their friends than about their siblings. These findings are consistent with earlier work reporting that first-born children are more prosocial and playful with a friend than with a sibling (Abramovitch, Corter, Pepler, \& Stanhope, 1986) and make more positive and fewer negative remarks about a friend than about a sibling (Stillwell, 1985).

Why should it be the case, though, that children's friendships are more positive than their sibling relationships? It is possible that children have different goals in friendships than in sibling relationships, and that different social rules govern their behavior in these relationships. As Shantz and Hobart (1989) have pointed out, friendships and sibling relationships place different demands on children; the former may promote connectedness between children, whereas the latter may foster the development of individuation. Because children tend to choose their friends, the establishment and maintenance of friendships are often based on mutual regard, cooperation, and trust. Conflicts must be handled diplomatically, and a degree of cooperation and mutual regard maintained to ensure continuation of the relationship. Siblings, on the other hand, share many common resources and often fight about personal property, parental attention, and privacy (Raffaelli, 1989). Repeated conflict may result in more negative feelings toward a sibling than toward a close friend and, because the sibling relationship is maintained through family ties, there is less need to focus on positive feelings to continue the relationship. At the same time, the nature of social conflict requires that the child take a stand against others and others take one against the child--acts that may encourage individuation and a sense of self (Shantz \& Hohart, 1989).

Consistency in individual differences across young children's friendships and sibling relationships was found to be limited. Maternal reports indicated that friendly interaction between friends at five years 
was positively associated with friendly interaction between siblings at six. Similarly, there was a trend for observed conflict with friends at five to be related to observed sibling conflict at six. In general, though, the findings suggest that, while the two kinds of relationship have some dimensions in common (e.g., warmth and friendliness), each has unique properties and serves different purposes. The relative independence of certain relationship dimensions across sibling and friend dyads suggests that each relationship may make independent contributions to children's adjustment and social development.

Several inverse associations that were found between the quality of friendship and sibling relationships deserve comment. It is possible that the findings reflect random error in the data; further research should attempt to replicate the current results. On the other hand, the findings are consistent with a growing body of literature underscoring the compensatory role of children's social relationships. It is quite likely that multiple processes mediate the connections between children's friend and sibling relationships, and that children may compensate for deficiencies in their social relationships (East \& Rook, 1992; Stocker, 1994). In the present study, children reported more negative feelings about their siblings when mothers reported more friendly behavior between the children and their friends at five years. A similar association was found in a study of 5-10-yearold children (Stocker and Dunn, 1990) in which maternal reports of sibling hostility were positively correlated with children's reports of friendship closeness. In the current study, those children reporting more negative feelings for their friend at five years were observed to cooperate more with their sibling at six; this is consistent with East and Rook's (1992) results indicating that children isolated by their schoolage peers perceived their friendships as least supportive and their favorite sibling relationship as most supportive.
The processes potentially responsible for these compensatory linkages between the sibling and friend dyads should be considered. One possibility is that children actively seek out warmth and support in social relationships with friends if it is not forthcoming in their family relationships, or vice versa (Dunn \& McGuire, 1992; East \& Rook, 1992). Dunn (1993) offered another plausible explanation for compensatory associations, arguing that children's developing capacity for social understanding emerges from experiences in sibling conflict and that these cognitive advances allow the child to develop a close relationship with a friend. Collectively, these findings underscore the many different functions that young children's social relationships may serve (Furman \& Buhrmester, 1985) and the possibility that multiple processes are responsible for the connections between their social relationships (Dunn, 1993).

In addition, the social world of young children includes many other participants (Bronfenbrenner, 1979). Children's friendships and sibling relationships are embedded within a complex social network that includes parents, teachers, extended family, and neighbors. The focus of the present study on only two dyads may at least partially explain the limited findings.

Several caveats should be mentioned regarding the generalizability of these findings. First, because the children's friendship and sibling relationships were assessed at different ages, there is a potential confound between age and the relationship assessed. Although most theoretical discussions of the development of children's social relationships underscore the changes between the early and middle childhood years (Parker \& Gottman, 1989), it is possible that the age of the child at the time of assessment played some part in the associations found. Second, first-born children and their relationships with a younger sibling and a close friend were the focus of the present study. Different findings might 
emerge in examining differences and similarities across a second-born's relationships with an older sibling and a close friend. The effect of birth-order on such relationship patterns is a matter for further study. Third, the processes responsible for linking sibling and friend relationships may not be the same as those mediating the connections between children's sibling relationships and their peer-group acceptance. Finally, the linkages examined involved the social relationships of preschool children. It is highly likely that as children reach middle childhood and adolescence and acquire a greater capacity for emotional and social understanding, different processes will mediate the linkages (Dunn, 1993).

Although the current findings need replication before they can be regarded with confidence, they provide a direction for future research that examines not only the development of young children's social relationships with siblings and friends, but also the unique ways in which these relationships contribute to the children's psychosocial functioning.

\section{REFERENCES}

Abramovitch, R, Corter, C., \& Lando, B. (1979). Sibling interaction in the home. Child Development, 50, 997-1003.

Abramovitch, R., Corter, C., Pepler, D., \& Stanhope, L. (1986). Sibling and peer interaction: A final follow-up and a comparison. Child Development. 57, 217-229

Belsky, J., Gilstrap, B., \& Rovine, M. (1984). The Pennsylvania Infant and Family Development Project I: Stability and change in mother-infant and father-infant interaction in a family setting at one, three, and nine months. Child Development, 55, 692-705

Belsky, J., Youngblade, L.M., Rovine, M., \& Volling, B.L. (1991). Patterns of marital change and parent-child interaction. Journal of Marriage and the Family, 53, 487-498.

Brody, G., Stoneman, Z., \& MacKinnon, C. (1982). Role asymmetries in interactions among schoolaged children, their younger siblings, and their friends. (hild Development, 53, 1364-1370.

Bronfenbrenner, U. (1979). The ecology of human development: Experiments by nature and design. Cambridge, MA: Harvard University Press.

Bukowski, W.H., \& Hoza, B. (1989). Popularity and friendship: Issues in theory, measurement, and outcome. In T. Berndt \& (;.W. Ladd (Eds.), Peer relationships in child development (pp. 15-45). New York: Wiley.
Cohen, J. (1960). A coefficient of agreement for nominal scales. Educational and Psychological Measurement. 20, 37-46.

Dunn, J. (1983). Sibling relationships in early childhood. Child Development, 54, 787-811.

Dunn, J. (1988). The beginnings of social understanding. Cambridge, MA: Harvard University Press.

Dunn, J. (1993). Young children's close relationships: Beyond attachment. Newbury Park, CA: Sage Publications.

Dunn, J., Brown, J., Slomkowski, C., Tesla, C., \& Youngblade, L. (1991). Young children's understanding of other people's feelings and beliefs: Individual differences and their antecedents. Child Development, 62, 1352-1366.

Dunn, J., \& Kendrick, C. (1982). Siblings: Love, envy, and understanding. Cambridge, MA: Harvard University Press.

Dunn, J., \& McGuire, S. (1992). Sibling and peer relationships in childhood. Journal of Child Psychology and Psychiatry, 33, 67-105.

Dunn, J., \& Plomin, R. (1990). Separate lives: Why siblings are so different. New York: Basic Books.

East, P.L., \& Rook, K.S. (1992). Compensatory patterns of support among children's peer relationships: A test using school friends, nonschool friends, and siblings. Developmental Psychology, $28,163-172$.

Furman, W., \& Buhrmester, D. (1985). Children's perceptions of the personal relationships in their social networks. Developmental Psychology, 2l, 1016-1024

Hinde, R.A. (1979). Toward understanding relationships. New York: Academic Press.

Howe, N. (1991). Sibling-directed internal state Janguage, perspective taking, and affective behavior. Child Development, 62, 1503-1512.

Lamb, M.E. (1978). The development of sibling relationships in infancy: A short-term longitudinal study. Child Development, 49,1189-1196.

Lynch, M., \& Cicchetti, D. (1991). Patterns of relatedness in maltreated and nonmaltreated children: Connections among multiple representational models. Development and Psychopathology, 3, 207-226.

Mellor-Crummey, C. (1989). Social coping in children. Unpublished doctoral dissertation. University of Rochester, Rochester, NY.

Parke, R.D., \& Ladd. G.W. (Eds.). (1992). Familypeer relationships: Modes of linkage. H Iillsdale, $\mathrm{NJ}$ : Erlbaum.

Parker, J.. \& Asher, S. (1987). Peer relations and later personal adjustment: Are low-aceepted children at risk? Psychological Bulletin, 102, 357-389.

Parker, J., \& Asher, S. (1992). Beyond group acceptance: Friendship and friendship quality as distinct dimensions of peer adjustment. In W.H. Jones \& D. Perlman (Eds.), Advances in personal relationships (vol. 4). London: Kingsley.

Parker, J.G., \& Asher, S. (1993). Friendship and friendship quality in middle childhood: Links with peer group acceptance and feelings of loneliness and social dissatisfaction. Developmental Psychology, 29.611-621. 
Parker, J., \& Gottman, J. (1989). Social and emotional development in a relational context: Friendship interaction from early childhood to adolescence. In T.J. Berndt \& G.W. Ladd (Eds.), Peer relationships in child development (pp. 95-131). New York: Wiley.

Patterson, G.R. (1986). The contribution of siblings to training for fighting: A microsocial analysis. In D. Olweus, J. Block, \& M. Radke-Yarrow (Eds.), Development of antisocial and prosocial behavior: Research, theories, and issues (pp. 235-261). New York: Academic Press.

Pettit, G.S., \& Bates, J.E. (1990). Describing family interaction patterns in early childhood: A "social events" perspective. Journal of Applied Developmental Psychology, 11, 395-418.

Pettit, G.S., Dodge, K.A., \& Brown, M.M. (1988). Early family experience, social problem solving patterns, and children's social competence. Child Development, 59, 107-120.

Pettit, G.S., Harrist, A.W., Bates, J.E., \& Dodge, K.A. (1991). Family interaction, social cognition and children's subsequent relations with peers at kindergarten. Journal of Social and Personal Relationships, 8, 383-402.

Piaget, J. (1932). The moral judgement of the child. London: Routledge \& Kegan Paul.

Plomin, R, \& Daniels, D. (1987). Why are children in the same family so different from one another? $\mathrm{Be}$ havioral and Brain Sciences, 10, 1-60.

Puttalaz, M. (1987). Maternal behavior and children's sociometric status. Child Development, 58, 324-340.

Raffaelli, M. (1989, April). Conflict with siblings and friends in late childhood and early adolescence. Paper presented at the Biennial Meeting of the Society for Research in Child Development, Kansas City, MO.

Rushton, J., Brainerd, C., \& Pressley, M. (1983). Behavioral development and construct validity: The principle of aggregation. Psychological Bulletin. $94,18-38$.
Stillwell, R. (1985, April). Siblings and friends as percelved by six-year-old children. Paper presented at the Biennial Meeting of the Society for Research in Child Development, Toronto.

Shantz, C.U., \& H lobart, C.J. (1989). Social conflict and development: Peers and siblings. In T. Berndt \& G.W. Ladd (Eds.), Peer relationships in child development (pp. 71-94). New York: Wiley.

Stocker, C. (1994). Children's perceptions of relationships with siblings, friends, and mothers: Compensatory processes and links with adjustment. Journal of Child Psychology and Psychiatry. 35, 1447-1459.

Stocker, C.M., \& Dunn, J. (1990). Sibling relationships in childhood: Links with friendships and peer relationships. British Journal of Developmental Psychology. 8, 227-244

Sullivan, H.S. (1953). The interpersonal theory of psychiatry. New York: Norton.

Volling, B.L., \& Belsky, J. (1992). The contribution of mother-child and father-child relationships to the quality of sibling interaction: A longitudinal study. Child Development, 63, 1209-1222

Wellborn, J.G., \& Connell, J.P. (1987). Manual for the Rochester Package for Schools. Department of Psychology, University of Rochester. Rochester, NY.

Yeates, K.O., \& Selman, R.L. (1989). Social competence in the schools: Toward an integrative developmental model for intervention. Developmental Review, 9, 64-100.

Youngblade, L.M. (1990). Families and friends: Parent to child influences on patterns of interaction with a close friend. Unpublished doctoral dissertation, Department of Human Development and Family Studies, Pennsylvania State University.

Youngblade, L.M., \& Belsky, J. (1992). Parent-child antecedents of 5-year-olds' close friendships: A longitudinal analysis. Developmental Psychology, $28,700-713$

Youniss, J. (1980). Parents and peers in social development. Chicago: University of Chicago Press. 